\title{
Expression profiles in barley microspore embryogenesis
}

M. Muñoz-Amatriaín, J.T. Svensson, A.M. Castillo, L. Cistué, T.J. Close, M.P. Vallés

M. Muñoz-Amatriaín, A.M Castillo, L. Cistue, M.P.Vallés

Departamento de Genética y Producción Vegetal

Estación Experimental Aula Dei

CSIC, 50059, Zaragoza

Spain

J.T. Svensson, T.J. Close

Department of Botany \& Plant Sciences

University of California Riverside

CA 92521

USA

Present address

J.T. Svensson

Department of Plant Biology

University of Copenhagen

DK-1871 Frederiksberg C

Denmark 


\begin{abstract}
In barley, microarray technology has allowed to study the gene expression profiling associated with the stress pretreatment phase of microspore embryogenesis, where the reprogramming of microspores takes place. Transcriptome analysis of anthers before and after four days of mannitol pretreatment, revealed changes in the expression of 2,673 genes. A thorough study of these differentially expressed genes indicated that microspores maintained their cell cycle machinery in a steady state during stress pretreatment and underwent a major reorganization of metabolic pathways accompanied by a multidimensional stress response. Up-regulation of transcription factors related to stress responses and changes in developmental programmes took place during the pretreatment. Preliminary studies have indicated that YABBY5, ZML2, CURLY LEAF and ICE1 transcription factors have a stress pretreatment specific induction and, therefore, could play a direct role in microspore reprogramming.
\end{abstract}

\title{
Keywords
}

Barley, Expression profiling, Microarray, Microspore embryogenesis, Reprogramming, Stress pretreatment, Transcription factors

\section{Introduction}

Plant microspores can be diverted from their normal pollen developmental pathway towards an embryogenic route after exposure to a stress pretreatment. This process, termed microspore embryogenesis or androgenesis, has been widely used to produce doubled haploids for genetics and breeding programmes (Forster and Thomas 2005) and represents a suitable system to study plant cell totipotency and embryogenesis (Hosp et al. 2007).

Stress acts as a trigger to induce microspore embryogenesis and represents a key point where the reprogramming of microspores takes place. Although microspore embryogenesis can be induced by different stresses, in barley, higher regeneration efficiencies are obtained 
when microspores at the mid-late to late uni-nucleate stage are subjected to a combination of starvation and osmotic stress pretreatments, which is achieved by incubating anthers in a medium with mannitol (Hoekstra et al. 1992).

The first genes identified in barley as being differentially expressed in the early stages of microspore embryogenesis encoded a lipid transfer protein (ECLTP), a glutathione Stransferase (ECGST) and a previously unknown protein (ECA1, possibly an arabinogalactanlike protein) (Vrinten et al. 1999). In recent years, the availability of large sets of expressed sequence tags (ESTs) have triggered the development of macro- and microarray technology approaches that provide a rich source of information of the molecular processes that take place during microspore embryogenesis, specially at the microspore reprogramming phase (Maraschin et al. 2006; Muñoz-Amatriaín et al. 2006).

In this chapter we show an analysis of gene expression profiling associated with mannitol stress pretreatment, obtained by using the Barley1 GeneChip (Close et al. 2004).

\section{Expression profile associated with stress pretreatment}

Transcriptome analysis of anthers before and after four days of stress pretreatment resulted in a broad overview of the mechanisms underlying the developmental transition from gametogenesis to embryogenesis (Muñoz-Amatriaín et al. 2006). The stress pretreatment consisted of incubating the anthers in a medium containing $0.7 \mathrm{M}$ mannitol, $40 \mathrm{mM} \mathrm{CaCl} 2$ and $8 \mathrm{~g} / \mathrm{l}$ agarose, for four days at $25^{\circ} \mathrm{C}$ in the dark (Cistué et al. 2003). The recently developed Barley1 GeneChip (Close et al. 2004) was used for this study, thus enabling the analysis of more than 22,000 genes simultaneously.

A stringent statistical approach was adopted (False Discovery Rate adjusted P-value cut-off of 0.01 , followed by filtering for four-fold or greater changes) resulting in a total of 2,673 differentially expressed genes, which revealed large changes in the transcriptome as a consequence of the mannitol pretreatment applied (Fig. 1). From these genes, 887 were upregulated after the pretreatment whereas 1,786 were down-regulated, indicating that these differences could be mainly due to a decrease in gametophytic information. 


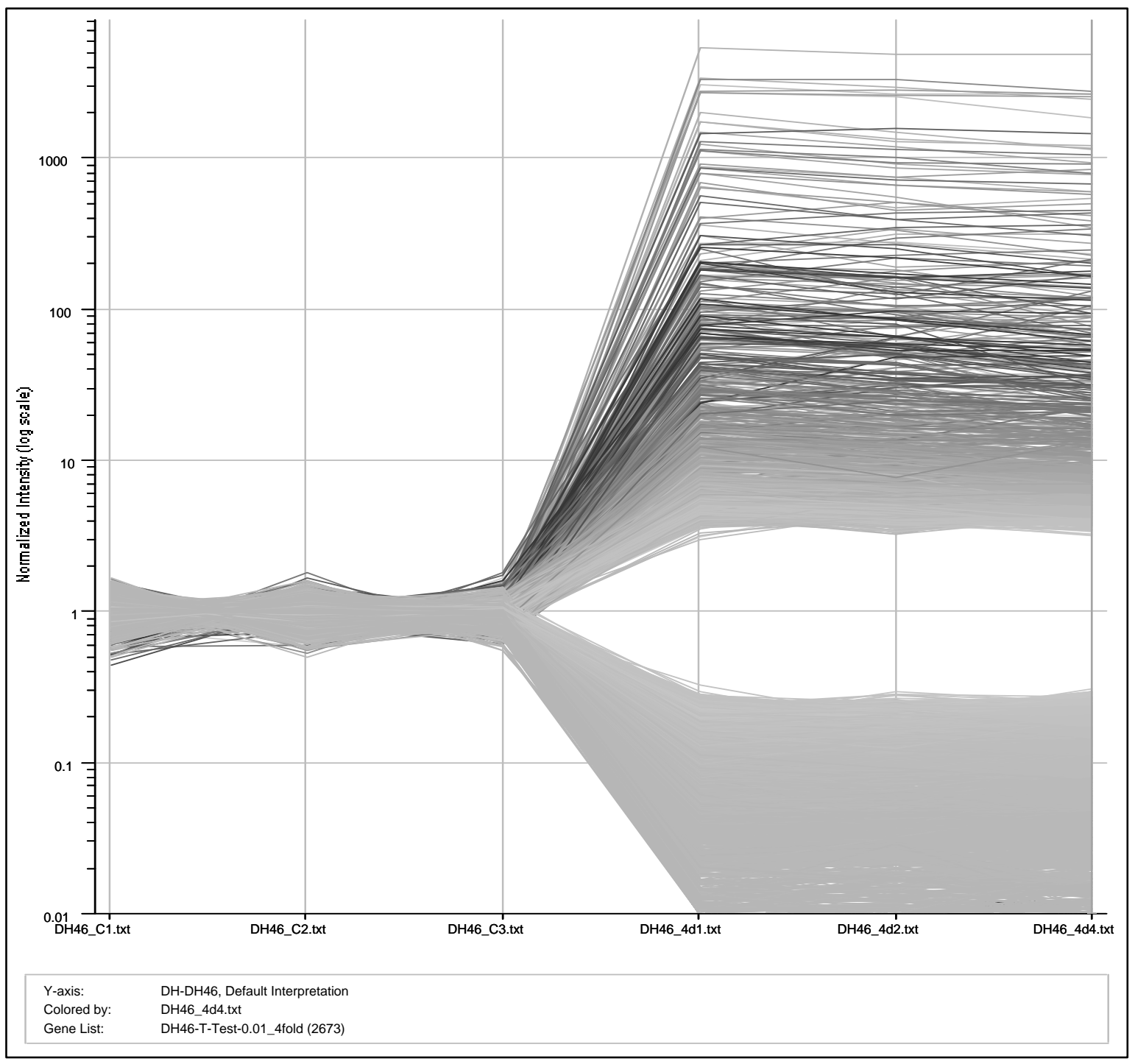

Fig. 1 Expression profile between zero and four days of mannitol pretreatment (False Discovery Rate adjusted P-value=0.01, 4-fold filtering). Three replicates from each condition are shown: C1, C2 and C3 are control replicates, and 4d1, 4d2 and 4d4 are 4-days after mannitol pretreatment replicates.

Functional classification of the differentially expressed genes was done using the MIPS database (http://mips.gsf.de/). Analysis revealed that $40 \%$ belonged to the category "unclassified proteins". Of the classified genes, more than $50 \%$ belonged to the categories "Metabolism" and "Energy", where most of the "metabolism" genes were involved in Ccompound and carbohydrate metabolism whereas the "energy" genes were related to glycolysis and gluconeogenesis. A thorough examination of genes belonging to these categories indicated that catabolism of reserve compounds such as starch, sucrose and lipids, was predominant over their biosynthesis. These expression data confirmed the reorganization 
of central carbon metabolism during carbohydrate starvation towards the flexible use of carbon skeletons from different sources, as already described for sugar starvation situations (Yu 1999; Contento et al. 2004).

Around $11 \%$ of the differentially expressed genes belonged to the "Cell rescue, defence and virulence" category. A multi-dimensional stress response was observed, since genes related to water deficit, osmotic stress, oxidative stress, phosphate starvation, cold stress, and response to wounding and pathogens were found. This is in agreement with the existence of complex networks in abiotic and biotic stress responses (Cheong et al. 2002). Among these stress-response genes, genes encoding glutathione S-transferases (GSTs) were overrepresented, representing a total of $2 \%$ of the up-regulated genes. GSTs are involved in oxidative stress response, pathogen attack and heavy metal toxicity (Marrs 1996) and the induction of members of the GST family during the initial steps of microspore embryogenesis has been described (Vrinten et al. 1999; Maraschin et al. 2006). With regard to heat shock proteins (HSPs), which have been reported to be highly expressed in microspores of rapeseed and tobacco upon heat shock and starvation (Cordewener et al. 1995; Zarsky et al. 1995; Smykal and Pechan 2000), only minor changes in the expression of the HSP genes were observed in this study. This is in agreement with the study of Malik et al. (2007) in Brassica, who found very few transcripts for HSPs in cDNA libraries of 3 day heat stress treatment.

In relation to the cell cycle, most genes were constitutively expressed, which might reflect maintenance of the cell cycle machinery in a steady state during mannitol pretreatment. CDC25, involved in the control of transition from G2 to M phase (Dewitte and Murray 2003) was one of the few genes with an increased expression after stress pretreatment, suggesting that the cell cycle is not arrested in G2.

\section{Transcription factor analysis}

Developmental programmes are controlled largely at the level of transcriptional regulation. The Barley1 GeneChip targets 340 genes encoding putative transcription factors and, of these, 79 were down-regulated and 27 were up-regulated after mannitol pretreatment.

Almost all members of families of: ethylene insensitive 3-like (EIL), auxin-response factors (ARF) and auxin-regulated proteins (Aux/IAA) decreased their expression after the stress pretreatment. ARF and Aux/IAA proteins play a critical role in most growth responses, controlling auxin-response genes (Hagen and Guilfoyle 2002). EIL participates in the 
ethylene signalling pathway, and its inhibition has been associated with cell growth inhibition and accelerated senescence (Guo and Ecker 2004).

The up-regulated transcription factors were divided into two groups according to the processes they regulated: abiotic and biotic stress responses (ICE1, ATAF2-like, WRKY46, AtbZIP60 and HSF7) and changes in developmental programmes (YABBY5, ZML2 and CURLY LEAF). Interestingly, we observed an induction of CURLY LEAF, a repressor of floral homeotic genes (Goodrich et al. 1997; Katz et al. 2004) together with the downregulation of the ABC model genes APETALA1, APETALA3, AGAMOUS and AGAMOUSLIKE 9 (AGL9). No transcription factors related to early embryo formation were found in this study.

The up-regulated transcription factors were compared to the barley reference experiment (Druka et al. 2006) to study their expression pattern in different tissues (Fig. 2). The expression patterns were very diverse: some transcription factors had a high level of expression in almost all tissues studied whereas others had very low level of expression in these tissues. 54\% of the transcription factors up-regulated after mannitol pretreatment were highly expressed in anthers.

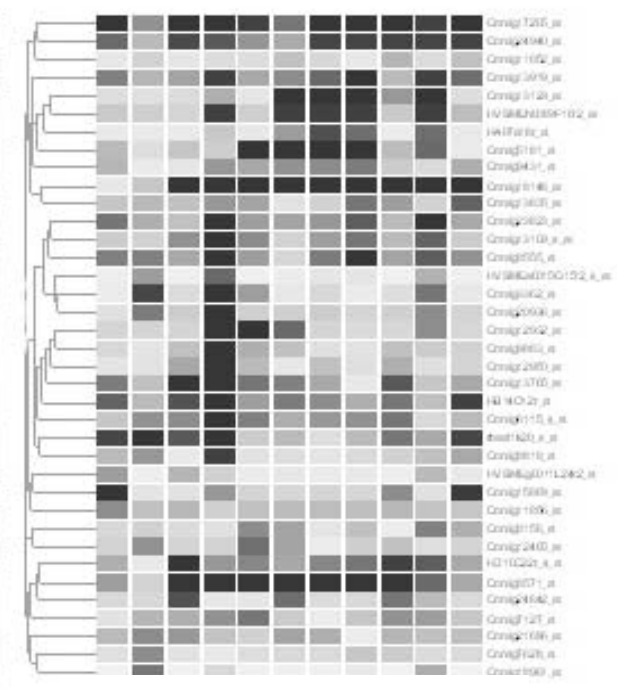

A B C D E F G H I J K

Fig. 2 Comparison of the Barley reference experiment versus the stress up-regulated transcription factors expression. Mannitol induced genes were compared to; (A) Root, (B) Leaf, (C) Inflorescence, (D) Anther, (E) Pistil (F) Caryopsis 5 DAP (Days After Pollination), (G) Caryopsis 10 DAP, (H) Caryopsis 16 DAP, (I) embryo 22 DAP, (J) endosperm 22 DAP and (K) Germinated seed. 
Although some transcription factors were up-regulated during mannitol stress pretreatment, no information related to the specificity of their expression in this phase was available.

Preliminary results have allowed us to compare the expression level of these transcription factors after zero, four days of mannitol pretreatment and three days of culture, where the sporophytic developmental pathway has started (Fig. 3). Out of the transcription factors down-regulated after pretreatment, $46.2 \%$ increased their expression at three days of culture. However, $72.9 \%$ of the up-regulated ones decreased their expression during culture. Thus, $52 \%$ of the transcription factors were differentially expressed at 4 days of stress pretreatment.

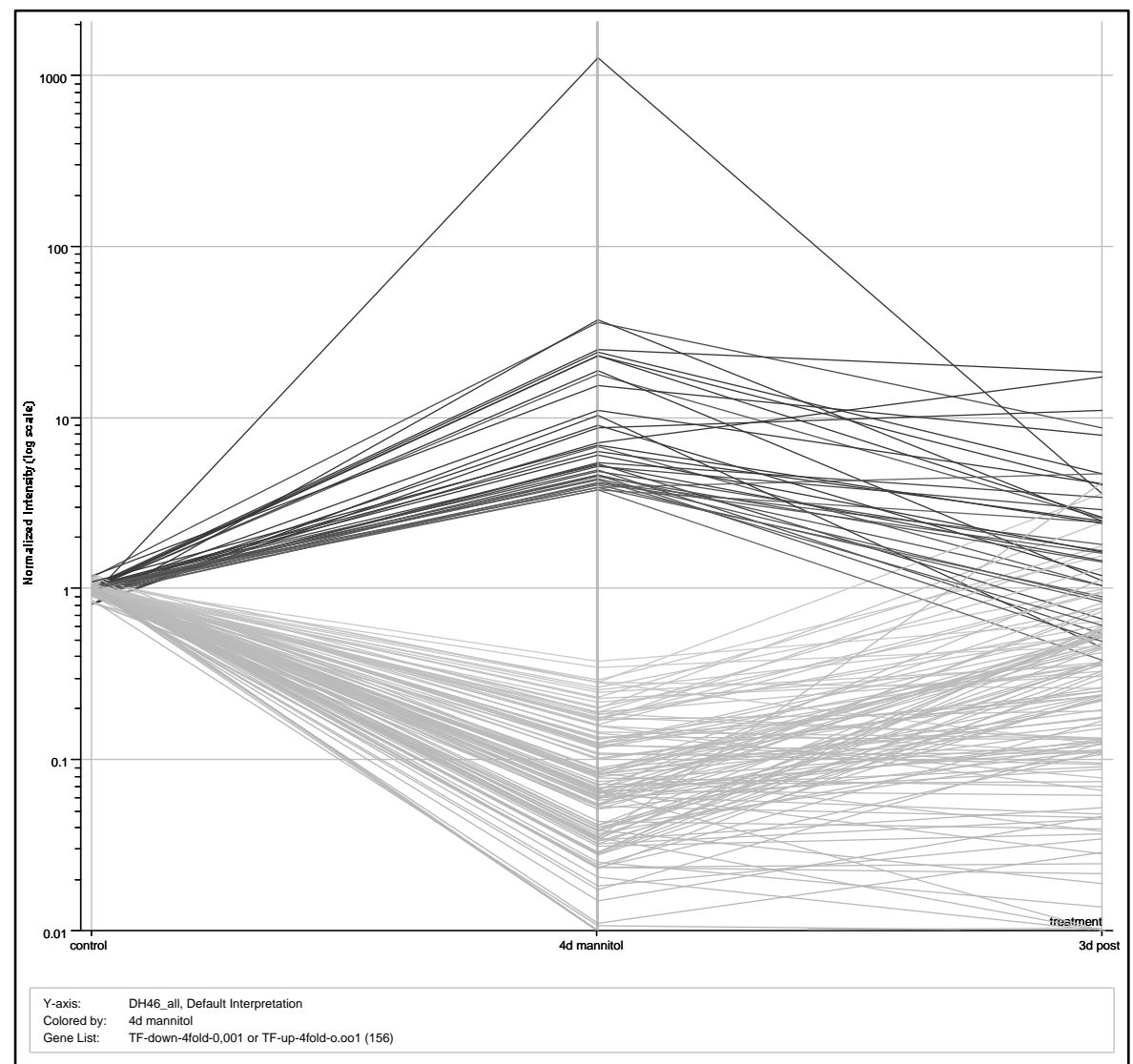

Fig. 3 Expression profile of the transcription factors between zero, four days of mannitol pretreatment and three days of culture (P-value=0.01, 4-fold filtering). 
The up-regulated transcription factors related to changes in developmental programmes as: YABBY5, with a role in meristem development and maintenance of stamens and carpels (Jang et al. 2004); ZML2, a C2C2 transcription factor associated with cell wall modifications during elongation (Shikata et al. 2004); and the repressor of floral homeotic genes CURLY LEAF, showed a stress pretreatment transient expression. Among those transcription factors related to abiotic and biotic stress responses, only ICE1, a MYC-like b-HLH transcriptional activator associated with cold and dehydration response (Chinnusamy et al. 2003), showed a stress pretreatment specific expression, whereas others as the HSF7 (Busch et al. 2005), maintained the same level of expression after 3 days of culture.

\section{Conclusions and perspectives}

DNA microarray technology has allowed the analysis of expression profiles of a large number of genes, before and after the stress pretreatment phase of microspore embryogenesis in barley. Barley microspores were found to undergo a dramatic change in their transcriptome as a consequence of the mannitol pretreatment, with major reorganization of metabolic pathways accompanied by a multi-dimensional stress response. Evidence of progression but not of arrest of the cell cycle was found. Transcription factor analysis indicated that the transcriptional control relied mainly on the protective roles to stress and suppression of the gametophytic developmental pathway, but without any evidence of embryogenesis initiation. In this way, after four days of mannitol stress pretreatment, barley microspores would be in a transitional de-differentiated phase.

Although, around 55\% of the up-regulated transcription factors were highly expressed in anther tissue, few of them had an anther-specific expression. Up-regulated transcription factors related to development showed a mannitol pretreatment specific induction, whereas only one of the transcription factors related to stress response was specifically induced by the pretreatment. Thus, YABBY5, ZML2, CURLY LEAF and ICE1 could play a direct role in microspore reprogramming. Previously in barley, Maraschin et al. (2006) revealed that genes encoding an alcohol dehydrogenase $3(\mathrm{ADH})$, and proteolytic genes as a metalloprotease FtsH, a cysteine protease precursor, an aspartic protease, and a 26S proteasome regulatory subunit, could represent bio-markers for the embryogenic potential of microspores. These 
results indicated that metabolic changes and proteolysis have a critical role in the dedifferentiation phase of microspore embryogenesis.

Further research is needed to characterise candidate genes playing a role in microspore reprogramming. Recently, studies using macro- and microarray technology have been used to further understanding of the molecular processes that take place in embryogenic microspores and microspore-derived embryos in Brassica (Pauls et al. 2006, Joosen et al. 2007, Malik et al. 2007). Although microspore embryogenesis is highly dependent on the species, genotype, stress pretreatment and culture media, utilization of microarray techniques is providing new insights into the molecular mechanisms that control microspore embryogenesis.

\section{References}

Busch W, Wunderlich M, Schöffl F (2005) Identification of novel heat shock factordependent genes and biochemical pathways in Arabidopsis thaliana. Plant J 41:1-14

Cistué L, Vallés MP, Echávarri B, Sanz JM, Castillo AM (2003) Barley anther culture. In: Malupszynski M, Kasha K, Foster B (eds) Doubled Haploid Production in Crop Plants. FAO/IAEA Division, Wien, A Manual, pp 29-35

Cheong YH, Chang H-S, Gupta R, Wang X, Zhu T, Luan S (2002) Transcriptional profiling reveals novel interactions between wounding, pathogen, abiotic stress and hormonal responses in Arabidopsis. Plant Physiol 129:661-677

Chinnusamy V, Ohta M, Kanrar S, Lee B-H, Hong X, Agarwal M, Zhu J-K (2003) ICE1: a regulator of cold-induced transcriptome and freezing tolerance in Arabidopsis. Genes Dev 17:1043-1054

Close TJ, Wanamaker S, Caldo RA, Turner SM, Ashlock DA, Dickerson JA, Wing RA, Muehlbauer GJ, Kleinhofs A, Wise RP (2004) A new resource for cereal genomics: 22K barley GeneChip comes of age. Plant Physiol 134:960-968

Contento AL, Kim SJ, Bassham DC (2004) Transcriptome profiling of the response of Arabidopsis suspension culture cells to Suc starvation. Plant Physiol 135:2330-2347

Cordewener JHG, Hause G, Görgen E, Busink R, Hause B, Dons HJM, Van Lammeren AAM, Van Lookeren Campagne MM, Pechan P (1995) Changes in synthesis and 
localization of members of the $70-\mathrm{kDa}$ class of heat-shock proteins accompany the induction of embryogenesis in Brassica napus L. microspores. Planta 196:747-755

Dewitte W, Murray JAH (2003) The plant cell cycle. Annu Rev Plant Biol 54:235-264

Druka A, Muehlbauer G, Druka I, Caldo R, Baumann U, Rostoks N, Schreiber A, Wise R, Close TJ, Kleinhofs A, Graner A, Schulman A, Langridge P, Sato K, Hayes P, McNicol J, Marshall D, Waugh R (2006) An atlas of gene expression from seed to seed through barley development. Funct Integr Genomics 6:202-211

Forster BP, Thomas WTB (2005) Doubled haploids in genetics and plant breeding. Plant Breeding Rev 25:57-88

Goodrich J, Puangsomiee P, Martin M, Long D, Meyerowitz EM, Coupland G (1997) A Polycomb-group gene regulates homeotic gene expression in Arabidopsis. Nature 386:4451

Guo H, Ecker JR (2004) The ethylene signalling pathway: new insights. Curr Opin Plant Biol 7:40-49

Hagen G, Guilfoyle T (2002) Auxin-responsive gene expression: genes, promoters and regulatory factors. Plant Mol Biol 49:373-385

Hoekstra S, van Zijderveld MH, Louwerse JD, Heidekamp F, van der Mark F (1992) Anther and microspore culture of Hordeum vulgare L. cv. Igri. Plant Sci 86:89-96

Hosp J, Maraschin SF, Touraev A, Boutilier K (2007) Functional genomics of microspore embryogenesis. Euphytica 158:275-285

Jang S, Hur J, Kim SJ, Han MJ, Kim SR, An G (2004) Ectopic expression of OsYAB1 causes extra stamens and carpels in rice. Plant Mol Biol 56:133-143

Joosen R, Cordewener J, Supena EDJ, Vorst O, Lammers M, Maliepaard C, Zeilmaker T, Miki B, America T, Custers J, Boutilier K (2007) Combined transcriptome and proteome analysis identifies pathways and markers associated with the establishment of rapeseed microspore-derived embryo development. Plant Physiol 144:155-172 
Katz A, Oliva M, Mosquna A, Hakim O, Ohad N (2004) FIE and CURLY LEAF polycomb proteins interact in the regulation of homeobox gene expression during sporophyte development. Plant J 37:707-719

Malik MR, Wang F, Dirpaul JM, Zhou N, Polowick PL, Ferrie AMR, Krochko JE (2007) Transcript profiling and identification of molecular markers for early microspore embryogenesis in Brassica napus. Plant Physiol 144:134-154

Maraschin SF, Caspers M, Potokina E, Wülfert F, Graner A, Spaink HP, Wang M (2006) cDNA array analysis of stress-induced gene expression in barley androgenesis. Physiol Plantarum 127:535-550

Marrs KA (1996) The functions and regulation of glutathione S-transferases in plants. Annu Rev Plant Physiol Plant Mol Biol 47:127-158

Muñoz-Amatriaín M, Svensson JT, Castillo AM, Cistué L, Close TJ, Vallés MP (2006) Transcriptome analysis of barley anthers: effect of mannitol treatment on microspore embryogenesis. Physiol Plantarum 127:551-560

Pauls KP, Chan J, Woronuk G, Schulze D, Brazolot J (2006) When microspores decide to become embryos - cellular and molecular changes. Can J Bot 84:668-678

Shikata M, Matsuda Y, Ando K, Nishii A, Takemura M, Yokota A, Kohchi T (2004) Characterization of Arabidopsis ZIM, a member of a novel plant-specific GATA factor gene family. J Exp Bot 55:631-639

Smycal P, Pechan PM (2000) Stress, as assessed by the appearance of sHsp transcripts, is required but not sufficient to initiate androgenesis. Physiol Plantarum 110:135-143

Vrinten PL, Nakamura T, Kasha KJ (1999) Characterization of cDNAs expressed in the early stages of microspore embryogenesis in barley (Hordeum vulgare L.). Plant Mol Biol 41:455-463

Yu SM (1999) Cellular and genetic responses of plants to sugar starvation. Plant Physiol 121:687-693

Zarsky V, Garrido D, Eller N, Tupy J, Vicente O, Schöffl F, Heberle-Bors E (1995) The expression of a small heat shock gene is activated during induction of tobacco pollen embryogenesis by starvation. Plant Cell Environ 18:139-147 